\title{
What Can Sudorimetry Tell us about Somatic and Autonomic Function
}

\author{
Marie Laure Névoret ${ }^{1 *}$ and Aaron I Vinik ${ }^{2}$ \\ ${ }^{1}$ ViroMed Co, Ltd. dba VM Bio Pharma, USA \\ ${ }^{2}$ Eastern Virginia Medical School, USA
}

Submission: June 08, 2018; Published: August 17, 2018

*Corresponding author: Marie Laure Névoret, Viro Med Co., Ltd. dba VM Bio Pharma, USA, Email: mnevore2002@yahoo.com

Keywords: Sudorimetry; Sudomotor function; Autonomic function; Cardiac autonomic neuropathy; Small fiber neuropathy

\section{A Short History of Pacing}

Small fiber neuropathy is on the increase and causes significant morbidity and mortality [1]. Peripheral C fiber dysfunction is a major cause of pain and sensory loss with loss of protective sensation and may be cryptogenic or part of the metabolic syndrome [2]. Cardiac autonomic neuropathy (CAN) is present in up to $90 \%$ of patients with type 1 and 20 $73 \%$ of patients with type 2 diabetes mellitus [3], and has been linked to resting tachycardia, intra-operative and perioperative cardiovascular instability, hypoglycemia unawareness, orthostatic hypotension, silent Myocardial Ischemia (MI), sudden death, and decreased survival after MI [4]. Autonomic symptoms and C fiber dysfunction appear too late in the development of neuropathy to be clinically relevant, and simple noninvasive early diagnostic testing is needed. Recently the Sudoscan device has been investigated as an early, simple, and rapid screening tool for CAN and somatic neuropathies [1]. While the Sudoscan test would be easy to implement categorically to screen the growing diabetes and prediabetes populations and other at risk patients, there remain questions regarding its exact mechanism and therefore skepticism in its applicability to detecting dysautonomia and small fiber dysfunction.

Sweat gland innervation is principally composed of postganglionic sympathetic cholinergic non-myelinated $\mathrm{C}$ fibers. Electrochemical Skin Conductance (ESC), the measure produced by the Sudoscan device, is described as an electrophysiological method forthe functional evaluation of sweat glands and related sudomotor/small fiber dysfunction [5,6]. Thus ESC is purported to measure an end-organ response as asurrogate marker of autonomic nerve function. ESC measurement is based on two physical principles: low voltage electrical activation of sweat glands and reverse iontophoresis to capture the flow of sweat chloride ions produced by activated sweat glands. During Sudoscan testing, subjects place both palms and soles on largearea stainless-steel electrodes. An incremental low direct voltage $(<4 \mathrm{~V})$ is applied for $15 \mathrm{~s}$ at each of the 4 electrodes. The voltage applied on skin electrodes generates a current between the anode and the cathode where ESC for that extremity is measured. ESC is calculated by the system's algorithm as the ratio of the current generated to the direct voltage stimulus and is expressed in micro Siemens $(\mu S)$. One ESC value is generated per extremity. Anumber of clinical studies have been published establishing ESC correlations with other measures of small fiber and autonomic nerve function, as well as normative values [7], accuracy and reproducibility [8]. Casellini et al. [1] used the Neuropathy Impairment Score of the Lower Limb (NIS-LL) $>2$ as the gold standard for defining diabetic peripheral neuropathy and established an AUC for Sudoscan of 0.88 [1]. This diagnostic accuracy was duplicated in 2 other studies $[9,10]$. More interesting than the sensitivity and specificity of $78.34 \%$ and $92.38 \%$, respectively, was a negative predictive value of $93.72 \%$ (also reflected in results by Smith et al. [9], practically eliminating any furtherneed for testing patients with normal ESC. The sensitivity and specificity of Sudoscan for the diagnosis of DSP has been shown to be in line with those of Intraepidermal Nerve Fiber Density (IENFD), and ESC are correlated (albeit modestly) with IENFD $[9,11]$. Sudoscan could be used to investigate CAN in diabetes and is well recognized in evaluating autonomic failure in familial amyloidosis [12,13]. Casellini [1]; Selvarajah [10]; Yajnik [14] all found significant correlations between ESC and cardiac autonomic functions, while Selvarajah [10] calculated a sensitivity of $65.0 \%$ and specificity of $80.0 \%$ for Sudoscan detection of CAN, in line with Yajnik's [14] sensitivity of $80 \%$ and specificity of 54\%. And in a longitudinal study of obese subjects undergoing bariatric surgery, changes in autonomic measures correlated significantly with changes in heart rate and ESC [15]. 
ESC values appear to reflect sweat gland dysfunction, caused by both neurological and non-neurological disorders [16]. Reduced ESC measurements may be caused by several mechanisms, including loss of sudomotor fibers, sweat gland atrophy, reduced number of sweat glands, or glandular dysfunction caused by toxic, metabolic, or other disorders [16]. In clinical practice, it remains unclear if Sudoscan voltage activates sweat glands or sudomotor nerves. The theoretical basis for ESC measurement has been demonstrated in the lab using various electrolyte baths and Chizmazdhev's model $[6,17]$ but cannot confirm the physiological process within human skin. Therefore, as Novak [16] suggests, testing the target of Sudoscan voltage activation could be possible clinically usinganticholinergic medication administration, patients with congenital absence of sweat glands or those with congenital absence of cholinergic sudomotor nerves. Another issue concerns the minimal change of Sudoscan ESC conductances with age [7] when sweat function is known to decrease significantly with age. This may be explained by Sudoscan measuring a flow of chloride ions in response to a supra-physiological applied voltage rather than measuring a volume of sweat-but has not been fully demonstrated. A further unexplained finding is the need to adjust ESC for weight in correlations with IENFD [11].

In conclusion, the in vivo physiology of Sudoscan testing may not be fully elucidated, but [1] a large amount of clinical data show consistent diagnostic value in rapid detection of small fiber and autonomic dysfunction, suggesting that Sudoscan already has value in daily clinical practice; and [2] simple trials could be devised to answer many of these questions. There is a lack of widespread autonomic testing in a growing at-risk adult population and ESC measures are currently the simplest and most accessible noninvasive screening exam available to identify the most urgent cases of small fiber and autonomic dysfunction.

\section{Conflict of Interest Statement}

AI Vinik has received research support from Impeto Medical Inc.; ML Nevoret is a past employee and current consultant of Impeto Medical Inc. No funding was received for the writing of this manuscript.

\section{References}

1. Casellini CM, Parson HK, Richardson MS, Nevoret ML, Vinik Al (2013) Sudoscan, a noninvasive tool for detecting diabetic small fiber neuropathy and autonomic dysfunction. Diabetes Technol Ther 15(11): 948-953.

2. Themistocleous AC, Ramirez JD, Serra J, Bennett DL (2014) The clinical approach to small fibre neuropathy and painful channelopathy. Pract Neurol 14(6): 368-379.
3. Dimitropoulos G, Tahrani AA, Stevens MJ (2014) Cardiac autonomic neuropathy in patients with diabetes mellitus. World J Diabetes 5(1): 17-39.

4. Vinik AI, Erbas T, Casellini CM (2013) Diabetic cardiac autonomic neuropathy, inflammation and cardiovascular disease. J Diabetes Investig 4(1): 4-18.

5. Ayoub H, Calvet JH, Lair V, Griveau S, Bedioui F, et al. (2012) Electrochemical basis for EZSCAN/SUDOSCAN: a quick, simple, and non-invasive method to evaluate sudomotor dysfunctions. In: Chun JH (Ed.), Developments in electrochemistry.

6. Ayoub H, Lair V, Griveau S, Brunswick P, Bedioui F, et al. (2012) Electrochemical characterization of stainless steel as a new electrode material in a medical device for the diagnosis of sudomotor dysfunction. Electro Analysis 24(6): 1324-1333.

7. Vinik AI, Smith AG, Singleton JR, Callaghan B, Freedman BI, et al. (2016) Normative values for electrochemical skin conductances and impact of ethnicity on quantitative assessment of sudomotor function. Diabetes Technol Ther 18(6): 391-398.

8. Bordier L, Dolz M, Monteiro L, Névoret ML, Calvet JH, et al. (2016) Accuracy of a rapid and non-invasive method for the assessment of small fiber neuropathy based on measurement of electrochemical skin conductances. Front Endocrinol 7: 18.

9. Smith AG, Lessard M, Reyna S, Doudova M, Singleton JR (2014) The diagnostic utility of Sudoscan for distal symmetric peripheral neuropathy. J Diabetes Complications 28(4): 511-516.

10. Selvarajah D, Cash T, Davies J, Sankar A, Rao G, et al. (2015) SUDOSCAN: A Simple, Rapid, and objective method with potential for screening for diabetic peripheral neuropathy. PLoS One 10: e0138224.

11. Novak P (2016) Electrochemical skin conductance correlates with skin nerve fiber density. Front Aging Neurosci 8: 199.

12. Castro J, Miranda B, Castro I, de Carvalho M, Conceição I (2016) The diagnostic accuracy of sudoscan in transthyretin familial amyloid polyneuropathy. Clin Neurophys 127(5): 2222-2227.

13. Lefaucheur JP, Zouari HG, Gorram F, Nordine T, Damy T, et al. (2018) The value of electrochemical skin conductance measurement using Sudoscan ${ }^{\circledR}$ in the assessment of patients with familial amyloid polyneuropathy. Clin Neurophysiol 129(8): 1565-1569.

14. Yajnik CS, Kantikar V, Pande A, Deslypere JP, Dupin J, et al. (2013) Screening of cardiovascular autonomic neuropathy in patients with diabetes using non-invasive quick and simple assessment of sudomotor function. Diabetes Metab 39(2): 126-131.

15. Casellini CM, Parson HK, Hodges K, Edwards JF, Lieb DC, et al. (2016) Bariatric surgery restores cardiac and sudomotor autonomic c-fiber dysfunction towards normal in obese subjects with type 2 diabetes. PLoS One 11(5): e0154211.

16. Novak P (2017) Electrochemical skin conductance: a systematic review. Clin Auton Res doi: 10.1007/s10286-017-0467-x.

17. Khalfallah K, Ayoub H, Calvet JH, Neveu X, Brunswick P, et al. (2010) Non-invasive galvanic skin sensor for early diagnosis of sudomotor dysfunction: application to diabetes. IEEE sensors Journal 12(3): 456463. 
Your next submission with Juniper Publishers will reach you the below assets

- Quality Editorial service

- Swift Peer Review

- Reprints availability

- E-prints Service

- Manuscript Podcast for convenient understanding

- Global attainment for your research

- Manuscript accessibility in different formats

( Pdf, E-pub, Full Text, Audio)

- Unceasing customer service

Track the below URL for one-step submission https://juniperpublishers.com/online-submission.php 